\title{
Interconexão entre Direito e bioética à luz das dimensões teórica, institucional e normativa
}

Natália Maria Soares Carreiro ${ }^{1}$, Aline Albuquerque S. de Oliveira ${ }^{2}$

\section{Resumo}

O presente artigo objetiva analisar a interconexão entre Direito e bioética tendo como foco as contribuições deste novo saber para os aplicadores do Direito na sua função de harmonização do convívio social. Para tanto, utilizou-se linha de pesquisa que propõe o recurso de dividir a bioética em três perspectivas: teórica, institucional e normativa. A partir de cada um desses enfoques, analisou-se os pontos de contato entre os dois saberes, bem como o modo em que a bioética concorre para o aprimoramento do Direito. Constatou-se que a bioética pode auxiliar o Poder Judiciário e o aplicador do Direito a compatibilizar a racionalidade jurídica com a reflexão ética propiciada por novos paradigmas científicos, contribuindo, assim, para a diminuição das dificuldades surgidas na busca de soluções para questões complexas relativas a conflitos nas áreas das ciências da vida, medicina e tecnologias associadas.

Palavras-chave: Direito. Bioética.

\section{Resumen}

La interconexión entre el Derecho y la bioética a la luz de sus dimensiones teórica, institucional y normativa

Este artículo tiene como objetivo analizar la interconexión entre el derecho y la bioética, centrándose en las contribuciones de este nuevo conocimiento para encargados de hacer cumplir la ley en su tarea de armonización de la vida social. Para este fin, se utilizó una línea de investigación que propone como recurso la división de la bioética en tres dimensiones: la bioética teórica, institucional y normativa. A partir de cada uno de estos enfoques, se analizaron los puntos de contacto entre los dos conocimientos, así como la manera que la bioética que contribuye a la mejor comprensión del Derecho. Se comprobó que la bioética puede ayudar al Poder Judiciario y al aplicador de la ley a conciliar la racionalidad legal con el pensamiento ético fomentado por nuevos paradigmas científicos, contribuyendo de esa forma para las cuestiones complejas relacionadas a conflictos en ámbito de las ciencias de la vida, médica y tecnologías adjuntas.

Palabras-clave: Derecho. Bioética.

\section{Abstract}

The interconnection between Law and bioethics in the light of their theoretical, institutional, and regulatory dimensions

This article aims to analyze the interconnection between Law and bioethics, focusing on the contributions of this new knowledge to the enforcers of Law in its function of social harmonization. For this purpose, we used the research line which features splitting bioethics into three perspectives: theoretical Bioethics, institutional and regulatory, and from each of these approaches, we analyzed the points of contact between the two fields of knowledge, and how bioethics contributes to the improvement of the Law. It was found that bioethics, helps the Judiciary Power and the ones who work with Law to deal with the complexity of issues related to life sciences, medicine and associated technologies.

Key words: Law. Bioethics.

1. Mestre natalia.carreiro@trf1.jus.br 2. Doutora alineaoliveira@hotmail.com - Programa de Pós-graduação em Bioética da Universidade de Brasília, Brasília/DF, Brasil.

Correspondência

Natália Maria Soares Carreiro - SHIS QI 25, conjunto 7, casa 4, Lago Sul CEP 71660-270. Brasília/DF, Brasil.

Declaram não haver conflito de interesse. 
No século $X X$, a humanidade assistiu ao vertiginoso desenvolvimento tecnocientífico, bem como despertou para a imperiosidade de construir aportes teóricos para a reflexão acerca do impacto desse incremento tecnocientífico nos seres humanos e no planeta. Desse modo, indaga-se se a espécie humana está preparada para lidar com os resultados advindos de seu potencial criativo, à medida que essa capacidade conduz ao aprimoramento das condições de vida e, concomitantemente, à sua própria dizimação.

Ponderando essa potencialidade, fica evidente o poder humano de transformar a natureza e o espaço geográfico. Entretanto, quando levados em conta os riscos de tal proposta, é questionável se deve modificá-los indiscriminadamente. Acrescente-se a esse contexto de dúvidas e incertezas a conotação como atrocidade das práticas médicas cometidas por profissionais nazistas nos campos de concentração, que emergiu após a Segunda Guerra Mundial. Isto é, passou-se da visão corrente de que médicos e cientistas sempre visavam o benefício de seu paciente para outra, mais próxima da complexidade da atuação médica e científica, que compreende a possibilidade de sua atuação danosa.

Em resposta a essas e outras questões decorrentes da insegurança gerada pela potencial capacidade destrutiva humana e percepção matizada da medicina, surgiu, na década de 70, a bioética, na confluência das éticas aplicadas, cujo objetivo central é a aplicação das teorias éticas a âmbitos específicos do mundo social. Esse movimento que diz respeito à bioética, à ética dos negócios e à ética ambiental ${ }^{1}$ tem como escopo a promoção da reflexão filosófica sobre problemas de cunho eminentemente ético da contemporaneidade ${ }^{2}$.

Ante a complexidade dos questionamentos, restou evidente a necessidade de criar espaços multidisciplinares nos quais fosse possível refletir acerca da aplicação das teorias éticas ao mundo social, a fim de verificar quais prescrições concretas seriam indicadas a cada caso ${ }^{1}$. Nas questões relacionadas às ciências da vida, à medicina e tecnologias associadas esse espaço foi proporcionado pela bioética, que congrega saberes que se complementam, gerando soluções impensáveis a um ou outro, considerados isoladamente. Como decorrência dessa essência multidisciplinar, a abordagem bioética também é eminentemente multiprofissional, pois conta com a participação ativa de profissionais da Saúde, do Direito, filósofos, teólogos, sociólogos, antropólogos - o que acarreta perspectivas distintas de análise e de metodologia para enfocar e examinar objetos semelhantes ${ }^{3}$.
Em virtude de sua recente existência e de abarcar distintas áreas do saber, o estatuto epistemológico da bioética ainda está sendo traçado. Considerando a área jurídica pode-se constatar a pouca familiaridade acerca de seu conteúdo teórico e normativo, bem como sobre as instituições que desempenham funções essencialmente bioéticas. Sob tal ótica, este trabalho busca colaborar para a disseminação da bioética nos espaços jurídicos, de modo a demonstrar para o estudioso e o aplicador do Direito a imperiosidade de o saber jurídico abrir mais espaço para disciplinas de cunho zetético ${ }^{4}$.

Portanto, o presente artigo pretende examinar, especificamente, as relações entre Direito e bioética, a partir do estudo das dimensões teórica, normativa e institucional da bioética, com vistas a contribuir para alicerçar teoricamente o novo campo. Ao esquadrinhar sua interconexão com o Direito procura-se cooperar para a definição dos limites teórico-pragmáticos da bioética e, assim, concorrer para sua consolidação acadêmica.

\section{Bioética: histórico e conceito}

O termo bioética foi utilizado pela primeira vez no início dos anos 70, pelo oncologista estadunidense Potter ${ }^{5}$, que o vinculou a um enfoque ampliado do campo nascente, ou seja, um saber focado na avaliação ética da relação do homem com a biosfera, demonstrando, assim, sua preocupação com a interação entre a problemática ambiental e a reflexão ética. Desse modo, Potter preconizou a construção de uma bioética assentada não num profundo domínio do conhecimento técnico, mas no respeito aos valores humanos.

No pensamento potteriano, a bioética surge como espécie de saber reflexivo sobre a sobrevivência humana no planeta, aliando as ciências biológicas aos valores humanistas. A despeito do fato de que o termo bioética tenha surgido naquela década, alguns bioeticistas sustentam que a bioética é fruto do julgamento dos médicos nazistas, ocorrido na cidade de Nüremberg em 1947. No julgamento comprovou-se que experimentos feitos em nome do avanço científico foram realizados por médicos com pessoas detidas nos campos de concentração, independentemente de seu consentimento.

A flagrante violação do juramento de Hipócrates - de fazer o bem e nunca causar mal - pôs em xeque a crença de que o médico sempre age visando ao interesse do paciente. Esse capítulo da história da humanidade fez aflorar a visão de que o desen- 
volvimento científico não deve alijar a verificação ética e a de que a beneficência da prática da medicina não é imanente, porque as condições de sua presença são socialmente forjadas. Embora não existisse o vocábulo bioética, o julgamento de Nüremberg e os princípios dele decorrentes, que estabeleceram parâmetros éticos para pesquisas envolvendo seres humanos, prenunciam o cerne da preocupação bioética sobre a eticidade do desenvolvimento científico e sua aplicação tecnológica, bem como dos valores morais e julgamentos em torno da relação médico-paciente ${ }^{6}$.

Consoante o acima exposto, o Código de Nüremberg ${ }^{7} \mathrm{e}$ a preocupação de cunho ético que o acompanha estariam situados na pré-história da bioética. Contudo, há argumentos de que a pré-história da disciplina iniciou-se na década de 50 , a partir da revolução biotecnológica desencadeada pela descoberta da estrutura do DNA por Crick e Watson e as consequentes questões éticas atinentes à genética humana. Outros apontam, ainda, a criação de um comitê de ética hospitalar composto por não médicos, na cidade de Seattle, Estados Unidos, no início da década de 70, como marco fundamental da inserção da reflexão ética no processo deliberatório na esfera da saúde. O comitê tinha a incumbência de selecionar pacientes para sessões de diálise dada a escassez de recursos para a realização do tratamento ${ }^{8}$.

A respeito do nascimento da bioética, além do mencionado Potter assinala-se o papel de igual relevância desempenhado por Hellegers, da Universidade de Georgetown, em Washington. Hellegers, pioneiramente, fundou o Joseph and Rose Kennedy Institute for the Study of Human Reproduction and Bioethics, introduzindo o termo bioética no ambiente acadêmico. Distintamente de Potter, focou o nascente saber em problemáticas ligadas à medicina e aos desafios trazidos pelo desenvolvimento tecnológico, quer pela escassez de recursos ou necessidade de conectá-la com questões populacionais ${ }^{8}$.

A bioética potteriana diz respeito à reflexão ética aplicada a temas ecológicos, ao passo que a hellegeriana é nitidamente centrada na medicina e suas interfaces, caracterizando-se como uma bioética biomédica. Ao examinar-se ambas as perspectivas, constata-se que no decorrer da construção histórica desse campo a bioética foi se amoldando à visão hellegeriana e, por conseguinte, sendo construída durante as décadas seguintes como um saber teórico-prático aplicado a dilemas morais ligados à área biomédica.

O ápice da bioética, de essência teórica, caracterizada como biomédica, consiste na publicação do livro de Beauchamp e Childress, em 1979, sobre os quatro princípios da ética biomédica: autonomia, beneficência, não maleficência e justiça. Apesar de manifestamente úteis para a resolução de problemas éticos nas esferas da biomedicina e da biotecnologia, esses princípios eram marcados por forte conotação individual. Em decorrência, não se revelaram adequados para a análise de problemáticas sociais relativas ao meio-ambiente e nem para as de ordem global, tais como patentes de medicamentos e pesquisa biomédica multicêntrica ${ }^{3}$.

Não obstante a relevância das temáticas abordadas pela bioética, esse campo manteve-se como que adormecido, cristalizado e restrito ao ambiente acadêmico e comitês específicos até o final dos anos 90, quando o estrondoso anúncio da clonagem da ovelha Dolly projetou a reflexão bioética nos meios de comunicação, de forma a ultrapassar os limites da academia e introduzir-se no debate público. A partir de então, pela necessidade de ampliação do campo de atuação da bioética e objetivando o enfrentamento de questões relacionadas a problemas específicos que afligiam as populações de baixa renda, acrescido à importância da adoção de uma visão crítica em relação à importação da produção teórica advinda dos países do Norte, surgiram críticas a essa abordagem que passou a ser alcunhada de principialismo ${ }^{9}$.

Surgiram, então, em diversos países, novas correntes que buscavam construir aportes teóricos adequados para a resolução de dilemas morais marcados pelos contextos sociais, econômicos e culturais nos quais se inseriam. Para citar algumas dessas vertentes teóricas, no Brasil tem-se a bioética de intervenção, que propõe uma posição confrontacional com enfoque nas questões concernentes à pobreza e injustiças sociais. Na Argentina, priorizou-se a defesa do respeito aos direitos humanos; em Cuba, o enfoque foi dado à solidariedade social sob a proteção de um Estado forte; no México, à depuração de políticas públicas corruptas; na Colômbia, à recuperação do diálogo civil; no Chile, à ética de proteção a serviço dos vulneráveis ${ }^{10}$.

A diversidade de construções bioéticas focadas em problemas sociais na América Latina demonstra que a bioética não se caracteriza como disciplina de base teórica uníssona, mas como um conjunto de vertentes teóricas marcadas pelas demandas sociais, que se refletem na atividade acadêmica de seus pensadores. Portanto, não existe uma bioética, mas várias bioéticas. Com efeito, em 2005, a partir da aprovação da Declaração Universal sobre Bioética e Direitos Humanos ${ }^{11}$ restou confirmado o caráter pluralista da bioética e ampliou-se definiti- 
vamente sua agenda para além da temática biomédica e biotecnológica, abarcando o campo social e ambiental ${ }^{12}$.

Justamente por essa diversidade de enfoques, árdua é a tarefa de estabelecer uma definição única para a bioética, o que dificulta, inclusive, o entendimento desse saber. Porém, partindo-se de determinadas características essenciais, é possível delimitar uma conceituação básica. Para tanto, recorre-se ao conceito proposto por Oliveira: ética aplicada, de natureza interdisciplinar, cuja apresentação se dá sob a forma de discursos e práticas, sendo que o aspecto que a distingue das demais análises éticas é ser direcionada para a tomada de decisões ${ }^{13}$.

Neste ponto, é necessário ressaltar que ainda existe resistência em rotular a bioética como ética. Entretanto, mesmo quem assim se posiciona acaba por situá-la nesse plano quando, ao fazer-lhe referência, utiliza expressões como assuntos éticos, reflexão ética ou escolhas éticas ${ }^{6}$. Tal dificuldade decorre da própria natureza da bioética, que permite conjugar sua essência interdisciplinar, ou seja, abarcadora de variadas disciplinas, tais como Medicina, Biologia, Direito e Filosofia, com a sua substância ética.

Para esclarecer esse ponto, é necessário que se diferencie o método, a natureza e o objetivo da bioética, isto é, sua natureza e seu objetivo são essencialmente éticos, porquanto objetiva a reflexão ética e a construção de um saber teórico-prático sobre questões ligadas à vida e à saúde. No entanto, seu método é interdisciplinar ${ }^{14}$. Com efeito, a bioética é entendida como um saber que se propõe a emitir prescrições, além de refletir sobre seu objeto: questões de ética suscitadas pela medicina, pelas ciências da vida e pelas tecnologias que lhes estão associadas, aplicadas aos seres humanos ${ }^{11}$. Esse campo de saber apresenta-se, portanto, não apenas na dimensão teórica, mas também como práxis institucionalizada e normativa.

Este artigo fundamenta-se nessas três dimensões da bioética para assentar sua conexão com o Direito. Para tanto, adotou-se linha de pesquisa, já publicada, desenvolvida por Oliveira ${ }^{6}$ em estudo acadêmico de doutorado em que a autora propõe a seguinte tripartição: bioética teórica, bioética institucional e bioética normativa - recorte que permite que essa disciplina, por ser objeto de conhecimento, seja estudada em seus variados modos de percepção.
A bioética e suas dimensões: teórica, institucional e normativa

A dimensão teórica pode ser definida como o conjunto de teorias e princípios cuja natureza é de ética aplicada e tem como objeto dilemas morais relacionados à saúde e à vida ${ }^{15}$. Nesse enfoque, dá-se ênfase às teorias e argumentações que estruturam a reflexão bioética. Isto não significa que se constitua em um conjunto de princípios e teorias universais e unívoco ${ }^{6}$, haja vista que as reflexões bioéticas tendem a tomar orientações mais ou menos adequadas aos ambientes histórico-culturais nos quais foram se desenvolvendo ou às orientações filosóficas ou religiosas que as sustentam ${ }^{16}$. Da pluralidade teórica da bioética decorre a existência de variadas correntes e escolas bioéticas com sustentações teóricas e práticas distintas e, às vezes, até antagônicas, sob as perspectivas ideológica, filosófica, religiosa e política ${ }^{6}$.

A bioética institucional envolve dois tipos de instituições: as que possuem funções cuja natureza é essencialmente bioética e as que apresentam papel variado, mas que se manifestam acerca de temáticas bioéticas. As primeiras são denominadas órgãos essencialmente bioéticos. Neste primeiro grupo enquadram-se os três tipos de comitês: de revisão ética de pesquisas envolvendo seres humanos; de aconselhamento ético em decisões clínicas; e os que possuem funções mais amplas relacionadas à avaliação do desenvolvimento científico e tecnológico, à formulação de diretrizes bioéticas e à promoção do debate e da educação em bioética.

No segundo tipo de instituição enquadram-se as instâncias que, embora não exerçam função de natureza essencialmente bioética, qual seja, de revisão ou análise ética, detêm competência para tratar de questões bioéticas ao examinar os desdobramentos éticos de determinadas ações ou promover o aprofundamento da reflexão bioética. Esses são intitulados instâncias de produção bioética ${ }^{6}$.

Quanto à terceira perspectiva estudada, Oliveira informa que a bioética normativa pode ser conceituada como o conjunto de normas bioéticas ${ }^{6}$. Com o fito de enquadrar determinada normativa como norma bioética, dois pressupostos devem estar presentes: um de ordem formal e outro material. A autora define que uma norma é bioética quando, além de ser fruto de um processo diferenciado e qualificado de produção, também traz comandos que, em verdade, são princípios bioéticos ${ }^{6}$. 
No tocante ao aspecto formal, o requisito recai sobre o modo como a norma foi produzida, ou seja, deve ter sido fruto de uma produção coletiva dialogada e democrática. Não importa, nessa classificação, se posteriormente houve acolhimento da proposição normativa por um poder estatal ou organismo internacional. A caracterização exigida aqui se refere aos debates ocorridos durante o processo legislativo, nos quais visões diferenciadas puderam ter sido colocadas e consideradas equanimemente.

O outro requisito da construção normativa em bioética refere-se ao conteúdo material das normativas, ou seja, aquilo que foi incorporado ao seu texto. Sendo assim, para que um instrumento jurídico seja caracterizado como inserto na bioética normativa deve conter princípios bioéticos. Dessa forma, seu conteúdo é eminentemente bioético, usualmente proveniente de proposições prescritivas advindas da bioética teórica.

A adoção de perspectiva tridimensional da bioética não implica asseverar que há distintas bioéticas, mas sim reconhecer que, para fins de análise de sua interconexão com outra área do conhecimento, importa definir o referencial tomado por base. Com efeito, a conexão teórica entre bioética e Direito irá apresentar características específicas. Do mesmo modo, na abordagem a partir da bioética normativa o olhar acerca da interconexão entre normas bioéticas e normas jurídicas também possui especificidades que precisam ser encaradas para que não se produza uma fórmula geral sobre como a bioética e o Direito se relacionam.

\section{Interconexão entre Direito e Bioética}

Considerando o viés normativo, a interface entre bioética e Direito é explícita, uma vez que há normas bioéticas que também apresentam natureza jurídica, tais como a Declaração Universal sobre o Genoma Humano e Direitos Humanos ${ }^{17}$, a Declaração Internacional sobre Dados Genéticos ${ }^{18}$ e a Declaração Universal sobre Bioética e Direitos Humanos ${ }^{11}$. Verifica-se a interpenetração entre os campos bioético e jurídico, ou seja, uma mesma norma pode ser percebida à luz do Direito e da bioética, em função de sua dupla natureza ${ }^{6}$.

Assim, Direito e bioética compartilham o arcabouço reflexivo que explicita o laço entre aquela disciplina e esse campo do conhecimento e impõem que estudiosos de ambos os saberes atravessem suas fronteiras a fim de lidar com a implementação dos referidos instrumentos. Isso ocorre porque, caso sua interpretação e aplicação se fundamentem tão somente em uma única disciplina, será incapaz de dar conta da complexidade da temática envolvida nas normas. Portanto, o estudo e a aplicação dos instrumentos que integram a bioética normativa pressupõem o diálogo entre o Direito e a bioética e a incorporação de aportes teóricos advindos de ambas.

No entanto, embora os dois saberes partilhem normas de conteúdo principiológico, o que conduz à construção de um novo modelo ético-legal fundamentado em normas que formulam racional fonte de argumentação em certa direção ${ }^{19}$, cabe assinalar que a bioética normativa não se confunde com biodireito. Este consiste num microssistema jurídico que regula a conduta humana em face dos avanços da biomedicina e biotecnologia ${ }^{2}$, abrangendo todas as normas jurídicas que possuem interface com temáticas bioéticas, independentemente da observância dos pressupostos de ordem material e formal, elencados no tópico anterior. Nota-se, destarte, que o conceito de biodireito é bem mais amplo do que o de bioética normativa ${ }^{6}$.

Nessa linha, nota-se que a bioética normativa atualmente se conforma mediante princípios que, segundo Alexy ${ }^{20}$, são mandamentos de otimização, normas que ordenam que algo seja realizado do modo mais eficaz possível dentro do arranjo fático e jurídico que o abarca.

Tais princípios encontram-se insertos em declarações e documentos de caráter obrigatório, como a Convenção de Oviedo ${ }^{21}$, aberta aos Estados-membros do Conselho da Europa, e outras de natureza não vinculante: a Declaração Universal sobre Genoma Humano e Direitos Humanos ${ }^{17}$, a Declaração Internacional sobre Dados Genéticos ${ }^{18}$ e a Declaração Universal sobre Bioética e Direitos Humanos ${ }^{11}$.

Desse modo, conclui-se que a produção em bioética trouxe para a esfera jurídica o balizamento normativo de questões éticas relacionadas à medicina, às ciências da vida e às tecnologias associadas quando aplicadas aos seres humanos, inovando ao alargar o âmbito de ingerência jurídica no mundo social. Princípios até então não vistos no Direito Internacional dos Direitos Humanos foram insertos nessa esfera de modo inovador: princípio do consentimento; princípio do respeito pela vulnerabi- 
lidade humana e integridade pessoal; princípio da não estigmatização e princípio dos efeitos benéficos e dos efeitos nocivos, todos previstos na Declaração Universal sobre Bioética e Direitos Humanos ${ }^{11}$.

Sendo assim, a bioética normativa oferta para o aplicador e estudioso do Direito uma gama de novos princípios que auxiliarão a prática jurídica, por meio do recurso a tais princípios, permitindo o deslinde de questões concretas. Para citar um exemplo, a Corte Europeia dos Direitos Humanos lançou mão do princípio do consentimento, contido no artigo 6 da Declaração sobre Bioética e Direitos Humanos ${ }^{11}$, para a apreciação do caso Evans versus Reino Unido sobre o uso de embriões humanos para fins de reprodução assistida ${ }^{22}$. Portanto, princípios bioéticos consubstanciados em documentos jurídicos são ferramentas hábeis para a construção de teses jurídicas novas, principalmente aquelas que têm como objeto as ciências da vida e a medicina.

Para a compreensão da interface entre bioética teórica e Direito, importante se faz retomar a noção da primeira, ou seja, a bioética teórica consiste, concisamente, na reunião de várias vertentes que desenvolvem teorias e métodos diferenciados. Na bioética teórica há uma gama de escolas reveladoras de que a bioética jamais foi singular ou unitária, mas, pelo contrário, revelou-se sempre, desde a sua gênese, como plural e diversificada ${ }^{23}$. Tendo em conta o pluralismo teórico presente em sua gênese, indaga-se como a bioética poderia, na condição de campo do conhecimento, interconectar-se com o Direito e contribuir para seu aprimoramento teórico-prático?

Inicialmente, importa assinalar que bioética teórica e Direito compartem princípios, à medida que, embora não haja univocidade entre as diversas correntes, pode-se afirmar que há um triunfo de uma bioética principiológica ${ }^{8}$. Sendo assim, a bioética teórica fundamenta-se, predominantemente, em um modelo teórico que parte de princípios morais para chegar a regras e, em sequência, numa deliberação concreta para o caso examinado ${ }^{24}$.

Em consonância com a bioética, com o advento do pós-positivismo no século passado a separação clássica propugnada pelo positivismo jurídico entre direito e moral é relativizada por meio da assunção de critérios de validade axiológicos da norma jurídica, bem como pela inserção em cartas constitucionais de preceitos normativos de natureza moral e que requerem do intérprete o recurso à moral para definir seu significado e conteúdo ${ }^{25}$. Com fulcro na conformação do ordenamento jurídico, advinda do pós-positivismo, pode-se afirmar que a interpretação e delimitação do âmbito de aplicação das normas jurídicas, notadamente as constitucionais, impõem ao seu agente o estudo das controvérsias éticas que as perpassam.

Sendo assim, o mero exame literal ou mesmo a investigação dogmática da norma não é suficiente para lidar com seu conteúdo moral e complexidade. Com efeito, nesse ponto se dá a contribuição da bioética teórica para o campo jurídico. Ao examinar os aspectos éticos envolvidos nos temas, a bioética teórica apresenta-se como aporte fundamental para a interpretação de normas jurídicas, propiciando, assim, ao intérprete fundamentação ética, algumas vezes não encontrada no Direito.

Com efeito, a bioética teórica oferece ao intérprete e aplicador do Direito substrato teórico de essência moral, apto a tornar sua tarefa interpretativa mais completa à proporção que considera os desdobramentos éticos da normativa. Também propicia ao rol dos aplicadores do Direito a possibilidade de se aproximarem da análise dos critérios de validade das normas, porquanto a correspondência entre $o$ seu conteúdo material e os valores ou o sistema de moralidade integra a perscrutação da validade ou invalidade da norma jurídica ${ }^{26}$.

Tendo em conta, ademais, que o atual horizonte constitucional no qual os princípios possuem força normativa e estatura máxima no ordenamento jurídico, a bioética teórica, por seu perfil principiológico e plasticidade, permite a aproximação do Direito com as moralidades que atravessam as temáticas ligadas às ciências da vida, à saúde e às tecnologias associadas. Sendo assim, o estudo da bioética pelo aplicador e acadêmico do Direito se revela essencial para a compreensão de determinados assuntos, bem como para a interpretação de normas jurídicas. O que se deve ao fato de a bioética teórica, mediante seus construtos, princípios e arcabouço de conhecimento, permitir que a análise de tais temáticas não seja alijada de sua conformação ética e técnica, abrindo o Direito para outras disciplinas e, mormente, assumindo o caráter axiológico das suas normas.

A bioética institucional, por sua vez, compreende o espaço onde efetivamente encontra-se a prática bioética. Nesse espaço institucional bioético, como apontado neste trabalho, há três tipos de comitês: de revisão ética de pesquisas envolvendo seres humanos; de aconselhamento ético em decisões clínicas; e os que possuem funções mais amplas relacionadas à avaliação do desenvolvimento científico e tecnológico, formulação de diretrizes bioéticas e promoção do debate e da educação em bioética. Enquanto lócus de confluência entre Direito e bioética institucional, os órgãos essencialmente bioéti- 
cos são produtores de normas, assentando prescrições para a sociedade, visando à harmonização do convívio social.

Os comitês de avaliação ética de pesquisas envolvendo seres humanos analisam protocolos de pesquisa e por meio de regramentos específicos emitem parecer aprovando ou não a condução da pesquisa submetida. Isso significa que, tal como o Poder Judiciário, emitem enunciados permissivos ou proibitivos de natureza concreta, os quais têm profundo impacto na atuação dos cientistas. Os comitês de aconselhamento ético em decisões clínicas ou de ética hospitalar, em linhas gerais, manifestam-se sobre conflitos bioéticos surgidos na prática do profissional de saúde, objetivando dirimi-los tarefa essa que também se assemelha a instâncias jurídicas que têm como fito a resolução de conflitos, principalmente as que lançam mão de técnicas de mediação.

Embora os comitês hospitalares também emitam prescrições, não se pode atribuir-lhes propriamente um papel julgador do objeto do conflito, tão somente buscam a apreciação do caso e prescrevem condutas sem caráter sancionatório. Quanto aos comitês nacionais de bioética, que são os relacionados à avaliação do desenvolvimento científico e tecnológico, formulam diretrizes bioéticas, ou seja, também exprimem prescrições de cunho abrangente, pois se direcionam a toda a sociedade e buscam balizar comportamentos, aproximando-se, assim, do fazer legislativo.

Tratando-se da contribuição da bioética institucional para a esfera jurídica, particularmente, o comitê de aconselhamento ético em decisões clínicas atua com vistas a obter a pacificação social por meio da resolução de conflitos morais. No mesmo sentido, o comitê de revisão ética de pesquisas envolvendo seres humanos revela prática preventiva quanto ao surgimento de conflitos jurídicos, à medida que eticamente regula a relação entre sujeito da pesquisa e pesquisador. Considerando que a bioética institucional exerce dupla função - além de ser espaço aberto ao diálogo atua na mediação de conflitos morais -, ela concorre para que as partes envolvidas não recorram ao Poder Judiciário, apresentando-se como mais um meio de resolução de conflitos jurídicos e desafogo do citado poder. Nesse caso, a contribuição da bioética institucional para o Direito encontra-se no fato de que os órgãos essencialmente bioéticos proporcionam meios alternativos de resolução de conflitos, dentre os quais se enquadra a mediação bioética ${ }^{27}$, o que se mostra importante no processo de instauração da cultura do diálogo e de mitigação da judicialização das contendas de natureza bioética.

\section{Considerações finais}

No presente estudo buscou-se verificar a conexão entre bioética e o Direito, à luz de três dimensões da bioética: normativa, teórica e institucional. Ainda, particularmente, objetivou examinar como esse campo de saber intermultidisciplinar e aberto à diversidade pode concorrer para auxiliar o aprimoramento do Direito, mediante socorro a seu aplicador e ao Poder Judiciário na solução de questões complexas e inéditas, relativas a conflitos nas áreas das ciências da vida, saúde e tecnologias associadas.

Desse modo, na esfera da bioética normativa, verificou-se que as normas bioéticas agregam, consubstanciadas em declarações e convenções internacionais, ao campo jurídico novos princípios, ampliando o elenco de normas principiológicas, o que torna o Direito mais apto a lidar com temáticas inexistentes até há pouco na história da humanidade, como pesquisa com células-tronco embrionárias e biobanco genético. A bioética normativa perfaz, na realidade, uma atualização do Direito e, simultaneamente, uma ampliação do seu espectro de atuação, tornando cobertos por normativas jurídicas temas que se encontravam na zona livre do Direito, o que acarretava insegurança jurídica e fragilidade das populações vulneráveis.

No âmbito teórico, a bioética, por meio de suas construções argumentativas, de princípios e discurso técnico proveniente da medicina e ciências da vida, possibilita que o aplicador do Direito aprofunde sua investigação da complexidade da perspectiva ética e contemple o caráter moral de tais normas quando estas tratarem de princípios constitucionais conectados com tais matérias. $O$ reconhecimento, inserto no pós-positivismo, da natureza moral de determinadas normas impõe o seu estudo sob essa perspectiva, o que inexoravelmente conduz ao campo bioético, com suas teorias e conhecimento próprios.

Ainda, constatou-se que a atuação dos comitês de revisão ética de pesquisa envolvendo seres humanos e os comitês de aconselhamento ético em decisões clínicas são genuínas instâncias de prevenção de demandas judiciais e fomento da cultura do diálogo. A atuação dos comitês de revisão ética previne a instauração de conflitos e os comitês de aconselhamento atuam quando já instaurados os conflitos, mediante meios variados de solução. Por- 
tanto, as instâncias da bioética institucional auxiliam o Poder Judiciário na manutenção da paz social, bem como colaboram para aliviar sua sobrecarga no atendimento das demandas da população.

Constatou-se que a bioética e o Direito apresentam interconexões evidentes e que esta, em suas três dimensões, pode vir a contribuir para o aprofundamento daquele, notadamente para a compreensão da norma jurídica enquanto prescrição axiológica. Verificou-se, ainda, que do reconhecimento da complexidade das temáticas bioéticas decorre a necessidade de o aplicador do Direito recorrer a saberes outros para a resolução de conflitos relacionados às ciências da vida, medicina e tecnologias associadas.

Por fim, a demarcação dos modos de penetração da bioética no campo jurídico contribui não apenas para este último, como também para a construção epistemológica da primeira. A bioética, em virtude de ser um saber cujas fronteiras ainda se encontram em processo de delimitação e seus aportes teóricos em desenvolvimento, demanda estudos de fundo analítico - tal como o proposto neste artigo - que busquem esquadrinhar suas dimensões teórica, normativa e institucional, bem como os seus modos de diálogo com outros campos do saber. Sendo assim, este artigo, embora apresente como foco precípuo a análise da penetração da bioética na esfera jurídica, ao esmiuçar tal interface concomitantemente aprofunda a reflexão sobre as perspectivas bioéticas e suas formas de aplicação, possibilitando pensar a bioética como uma disciplina aberta para as demais, à proporção que amplifica canais de comunicação com outros meios normativos de controle social.

\section{Referências}

1. Mori M. A bioética: sua natureza e história. Humanidades. [internet]. 1994 [acesso 30 abr. 2011];9(4):332-41. Disponivel: http://www.anis.org.br/Cd01/comum/TextoPosGraduacao/posgraduacao_texto_07_mori_port.pdf

2. Barboza HH, Meirelles JML, Barretto VP, organizadores. Novos temas de biodireito e bioética. Rio de Janeiro: Renovar; 2003.

3. Garrafa V. Introdução à bioética. Rev do Hospital Universitário da UFMA. 2005;6(2):9.

4. Ferraz Júnior TS. Introdução ao estudo do direito. São Paulo: Atlas; 2006.

5. Potter VR. Bioethics: bridge to the future. New Jersey: Prentice Hall; 1971

6. Oliveira AAS. Bioética e direitos humanos. São Paulo: Loyola; 2011.

7. Tribunal Internacional de Nuremberg. Código de Nuremberg. Projeto Ghente. [internet]. [acesso 27 fev. 2012]. Disponível: http://www.ghente.org/doc_juridicos/nuremberg.htm

8. Neves MCP, Osswald W. Bioética simples. Lisboa: Verbo; 2007.

9. Clouser D, Gert B. A critique of principlism. J Med Philos. 1990:15:219-36.

10. Kottow M. Bioética prescritiva: a falácia naturalista, o conceito de princípios na bioética. In: Garrafa V, Kottow M, Saada A, organizadores. Bases conceituais da bioética: enfoque latinoamericano. São Paulo: Gaia; 2006.

11. Organização das Nações Unidas para a Educação, a Ciência e a Cultura. Declaração Universal sobre Bioética e Direitos Humanos. Brasília: Unesco; 2006.

12. Garrafa V, Azambuja LEO. Epistemologia de la bioetica: enfoque latino-americano. Revista Brasileira de Bioética. 2007;3(3):344-59.

13. Oliveira AAS. Op. cit. p. 29.

14. Oliveira AAS. Op. cit. p. 24.

15. Oliveira AAS. Op. cit. p. 23.

16. Sauwen RF, Hryniewicz S. O direito "in vitro": da bioética ao biodireito. Rio de Janeiro: Lumen Juris; 2008.

17. Organização das Nações Unidas para a Educação, a Ciência e a Cultura. Declaração Universal sobre Genoma Humano e Direitos Humanos: da teoria a prática. [internet]. Brasília: Unesco; 1997 [acesso 27 fev. 2012]. Disponível: http://unesdoc.unesco.org/images/0012/001229/122990por.pdf

18. Organização das Nações Unidas para a Educação, a Ciência e a Cultura. Declaração Internacional sobre os Dados Genéticos. [internet]. Portugal: Unesco; 2004 [acesso 27 fev. 2012]. Disponível: http://bvsms.saude.gov.br/bvs/publicacoes/declaracao_inter_dados_genericos.pdf

19. Dworkin R. Levando os direitos a sério. São Paulo: Martins Fontes; 2002.

20. Alexy R. Teoria dos direitos fundamentais. São Paulo: Malheiros; 2002.

21. Conselho da Europa. Convenção para a Proteção dos Direitos do Homem e da Dignidade do Ser Humano face às aplicações da Biologia e da Medicina. [internet]. Oviedo; 1997 [acesso 27 fev. 2012]. Disponível: http://www.gddc.pt/direitos-humanos/textos-internacionais-dh/ tidhregionais/convbiologiaNOVO.html

22. European Court of Human Rights. Case of Evans v. The United Kingdom (Application $n^{\circ} 6.339 / 05$ ): judment. [internet]. Strasbourg; 2007 [19 set. 2011]. Disponível: http://hudoc.echr.coe.int/sites/ eng/pages/search.aspx?i=001-80046 
23. Neves MCP. Bioética e bioéticas. In: Neves MCP, Lima M, coordenadores. Bioética ou bioéticas: na evolução das sociedades. Coimbra: Centro de Estudos de Bioética-Polo Açores; 2002. p. 288.

24. Kymlicka W. Filosofia política contemporânea. São Paulo: Martins Fontes; 2006.

25. Vale AR. Estrutura das normas de direitos fundamentais. São Paulo: Saraiva; 2009. p. 28.

26. Vale AR. Op. cit.

27. Dubler NN, Liebman CB. Bioethics mediation: a guide to shaping shared solutions. Nashville, Tennessee: Vanderbilt University Press; 2011.

\section{Participação das autoras no artigo}

Natália Carreiro contribuiu com a pesquisa, levantamento de dados, elaboração do texto e revisão gramatical. Aline Oliveira contribuiu com a orientação, sugestão de temas, elaboração de ajustes no texto e revisão gramatical.

Recebido: 19.10 .2011

Revisado: 28.11 .2012

Aprovado: 18.2 .2013 